\title{
Laser Performance and Spectroscopic Analysis of Optically Written Channel Waveguides in Neodymium-Doped Gallium Lanthanum Sulphide Glass
}

\author{
Arshad K. Mairaj, Alain M. Chardon, David P. Shepherd, and Daniel W. Hewak
}

\begin{abstract}
We present a spectroscopic analysis and laser characterization of optically written waveguides in neodymium-doped gallium lanthanum sulphide $\left(\mathrm{Nd}^{3+}\right.$-Ga:La:S) chalcogenide glass. Uniform channel waveguides were fabricated in $\mathrm{Nd}^{3+}$-Ga:La:S by exposure to radiation from a focused UV-laser beam $(\lambda=$ $244 \mathrm{~nm}$ ), producing a refractive index change $\triangle n \approx+10^{-3}$. The observed laser performance and fluorescence decay were in good agreement with values calculated from a spectroscopic analysis of $85 \mu$ s for the ${ }^{4} F_{3 / 2}$ lifetime and $5.9 \times 10^{-20} \mathrm{~cm}^{2}$ for the emission cross section at $1075 \mathrm{~nm}$. Low threshold laser operation with emission at $1075 \mathrm{~nm}$ and a slope efficiency of $17 \%$ is demonstrated. The active device is spatially single mode and exhibits up to $8.6 \mathrm{~mW}$ of output power and propagation losses of $<0.5 \mathrm{~dB} \mathrm{~cm}^{-1}$. Waveguide fabrication, photoinduced effects, and optical characterization in terms of spectroscopy, laser performance, and device attenuation are discussed.
\end{abstract}

Index Terms-Amorphous semiconductor, optical writing, waveguide laser.

\section{INTRODUCTION}

$\mathbf{T}$ HE concept of integrated optics (IO), first conceived in 1969 [1], proposed the amalgamation of multiple devices such as switches, multiplexers, modulators, signal amplifiers, and lasers onto a single photonic chip in order to achieve highly functional and compact optical circuits. Silica-based materials are a possible host medium for such optical circuits and have been used for initial demonstrations of passive and active IO devices. Plasma-enhanced chemical vapor deposition (PECVD) enabled the uniform deposition of silicon oxynitride (SiON) layers with optical loss $<0.2 \mathrm{~dB} \mathrm{~cm}^{-1}$ at $1550 \mathrm{~nm}$ [2] and layers of $\mathrm{Er}^{3+}$-doped phosphosilicate glass with a gain coefficient of $0.67 \mathrm{~dB} \mathrm{~cm}^{-1}$ [3]. An extension of this waveguide fabrication technique involves using a focused CW UV-laser $(\lambda=244 \mathrm{~nm})$ beam to directly write buried single-mode channel waveguides into a germanosilicate film [4]. Several other methods, such as flame hydrolysis deposition [5], sol-gel processing and spin-coating [6], and ion-exchange [7] have also been used to produce active silica devices.

Manuscript received August 29, 2002; revised October 4, 2002. This work was supported in part by a DTI/EPSRC grant through the LINK Photonics Programme, Pirelli Cavi, and the EPSRC under Grant GR/N09787.

The authors are with the Optoelectronics Research Centre, University of Southampton, SO17 1BJ, U.K. (e-mail: mkam@orc.soton.ac.uk).

Digital Object Identifier 10.1109/JSTQE.2002.806672
However, the evolution of silica glass into a mature technology and its dramatic impact on telecommunications has also served to highlight its limitations in active planar operation. These include concentration quenching effects caused by the high rare-earth concentration necessary to compensate for the short interaction length, poor functionality as an optical switch, and an inability to transmit radiation much beyond $2 \mu \mathrm{m}$. The relentless drive toward exceeding the current state of the art in telecommunications, as well as other application areas, demands investigation into diverse fabrication techniques for a plethora of host materials that offer capabilities surpassing silica glass. The search for new nonoxide vitreous materials led to the development of fluoride and chalcogenide glasses (ChGs). Made from low phonon-energy materials, with heavier ions having weak bond strengths, these glasses can transmit light at much longer wavelengths [8], [9]. The practicability of low phonon-energy $\left(550 \mathrm{~cm}^{-1}\right)$ fluoride glasses as planar devices has been demonstrated through several processes including ion exchange [10], [11], physical vapor deposition (PVD) [11]-[13], and sol-gel synthesis [14]. Experiments in directly writing waveguides into $\mathrm{Nd}^{3+}$-doped fluoroaluminate [15] and PZG glass [11] with a CW UV-laser $(\lambda=244 \mathrm{~nm})$ have also been reported. Laser action at $1317 \mathrm{~nm}$ in the $\mathrm{Nd}^{3+}$-doped fluoroaluminate glass was enabled by combining the spin-coating and direct writing techniques. Laser pulses from a femtosecond laser $(\lambda=800 \mathrm{~nm})$ have also been used to fashion similar passive structures into fluorozirconate glass [16].

In this paper we concentrate on planar waveguides optically written in chalcogenide glasses, which have unique optical properties that make them very interesting for IO devices. These properties include very low phonon energies $\left(325-425 \mathrm{~cm}^{-1}\right)$, which allows many radiative transitions for rare-earth ions which are otherwise quenched in amorphous materials, high IR transparency, inherent photosensitivity, and a high nonlinear refractive index [9], [17], [18]. Notable previous works include quantum cascade lasers with $\mathrm{Ge}_{0.25} \mathrm{Se}_{0.75}$ glass claddings fabricated through pulsed laser deposition (PLD) [19], first- and second-order Bragg reflectors at $1500 \mathrm{~nm}$ in $\mathrm{As}_{2} \mathrm{~S}_{3}$ glass [20] and sol-gel processing of germanium sulfide planar waveguides [21]. Alternative manufacturing methods of optical waveguides in As:S:Se glass include photolithography and ion implantation [22]. Finally, demonstrations of waveguide writing into ChGs 
include using a femtosecond laser $(\lambda=850 \mathrm{~nm})$ in $\mathrm{As}_{2} \mathrm{~S}_{3}$ glass [23] and direct-UV $(\lambda=244 \mathrm{~nm})$ laser writing into Ga:La:S glass [24].

The gallium lanthanum sulphide (Ga:La:S) glass system described in this work is a vitreous chalcogenide material first discovered in 1976 [25]. Since then, interest has been maintained over the years primarily due to its exceptional optical properties. These glasses have a wide transmission window between 0.6-7 $\mu \mathrm{m}$ and are classed as an amorphous semiconductor with bandgap energy $2.6 \mathrm{eV}(475 \mathrm{~nm})$. The nontoxicity, high glass transition temperature, excellent rare-earth solubility, high refractive index $(n=2.3$ at $1 \mu \mathrm{m})$, low phonon energy, high nonlinearity, and photosensitive properties make it an interesting candidate for research into planar waveguide devices [26]. In a previous paper we reported the first laser operation of optically written channel waveguides in $\mathrm{Nd}^{3+}{ }_{-} \mathrm{Ga}: L a: S$ glass [27], and we now present in detail the spectroscopic properties of the channel waveguides in order to obtain a full characterization of such devices. Following this introduction, Section II details the direct writing of channel waveguides using a focused short-wavelength $(\lambda=244 \mathrm{~nm})$ source and the photoinduced effects resulting in material modification, including giantphotocompaction and photochemical modification. Section III describes device characterization in terms of absorption and fluorescence spectroscopy, laser operation $(\lambda=1075 \mathrm{~nm})$, and waveguide attenuation. Finally, in Section IV we give our concluding remarks and discuss the prospects for IO devices based in this host material.

\section{Channel WaVeguide FABRicAtion AND PHOTOINDUCED EFFECTS}

Fabrication of $\mathrm{Nd}^{3+}{ }_{-} \mathrm{Ga}: \mathrm{La}: \mathrm{S}$ glass, with a typical molar ratio $65 \mathrm{Ga}_{2} \mathrm{~S}_{3}: 31.5 \mathrm{La}_{2} \mathrm{~S}_{3}: 3 \mathrm{La}_{2} \mathrm{O}_{3}: 0.5 \mathrm{Nd}_{2} \mathrm{~S}_{3}$, was carried out from prepared batches of high purity $(6 \mathrm{~N})$ powders. These glass precursors were loaded into a vitreous carbon crucible while in a controlled atmosphere. The precursors are nonvolatile at the glass melting temperature $\left(1150{ }^{\circ} \mathrm{C}\right.$ for up to $24 \mathrm{~h}$ ) and were heated in an argon atmosphere, after which the melt was quenched and annealed. The glass was cut into slabs $(20 \times 17 \times 2 \mathrm{~mm})$ and polished on the top and bottom faces. An optically flat polish is required on the writing surface to minimize scattering of laser light during writing. Surface preparation plays an important role in minimizing the laser damage threshold due to dust, stains, and superficial scratches on the glass surface. As a final preparatory step prior to laser writing, the polished surface of the target sample was cleaned with isopropanol and methanol. After laser writing, the sample was polished at both end faces to allow optical coupling.

The direct-UV writing setup shown in Fig. 1 consists of a frequency-doubled UV laser (Coherent FRED Sabre 500) with $200 \mathrm{~mW}$ of CW output at $244 \mathrm{~nm}$. A UV-grade spherical fused silica lens (35 mm focal length) provides a focused writing spot from the spatially filtered laser beam. The UV beam spot size $\left(1 / e^{2}\right.$ radius of intensity) is approximately $3.1 \mathrm{~mm}$ and the measured spot size of the focused waist is $3.3 \mu \mathrm{m}$. The sample, held in place by a vacuum chuck, was attached to a computer-controlled translation stage. The stage, which

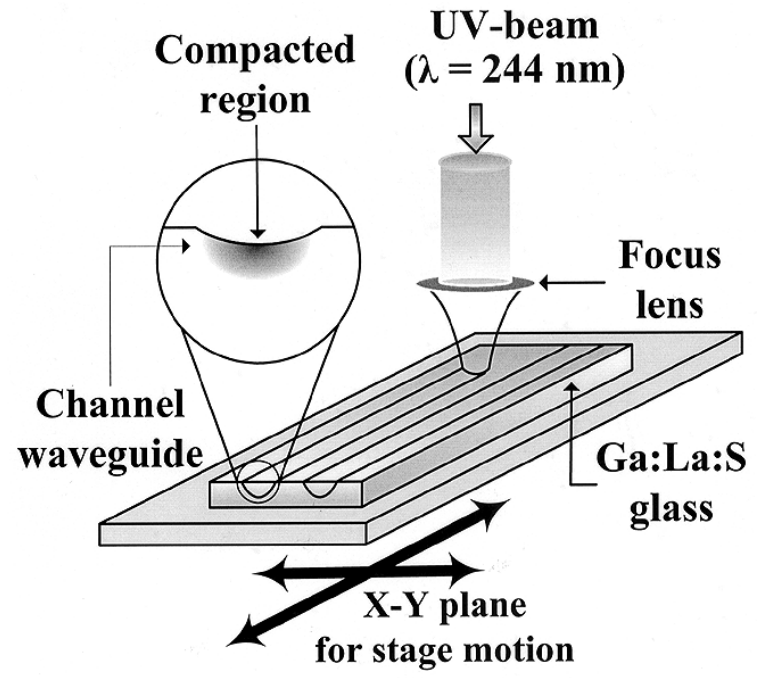

Fig. 1. Schematic diagram of the setup used to directly write channel waveguides into $\mathrm{Nd}^{3+}{ }_{-} \mathrm{Ga}: \mathrm{La}: \mathrm{S}$.

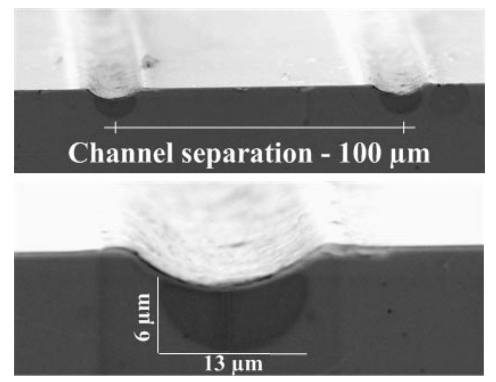

Fig. 2. Micrograph (SEM) of channel waveguides written with a laser fluence $10.8 \mathrm{~J} / \mathrm{cm}^{2}$. The close-up view shows a physical channel size of $13 \mu \mathrm{m}$ by $6 \mu \mathrm{m}$.

provided the two-dimensional (2-D) movement of the sample ( $X$ and $Y$ dimensions), has a maximum scan velocity of up to $5 \mathrm{~cm} / \mathrm{s}$ and relative position resolution of $0.1 \mu \mathrm{m}$. The quality and dimension of a channel waveguide was determined by both the intensity $\left(I_{\mathrm{UV}}\right)$ of the focused laser beam and the scan velocity $\left(V_{\mathrm{SCAN}}\right)$. The average laser fluence $(F)$ applied to the glass surface may then be calculated from [4]

$$
F \approx \frac{I_{\mathrm{UV} a}}{V_{\mathrm{SCAN}}}
$$

where $a$ is the spot size on the surface. Fig. 1 also indicates photostructural change in the form of giant-photocompaction with material densification. For our experiments, the $U V$ spot size was varied between $25-50 \mu \mathrm{m}$ by adjusting the sample to focus distance and this, together with adjustment of the power, provides a controllable intensity in the range of $I_{\mathrm{UV}}=1.5-10.2 \mathrm{~kW} / \mathrm{cm}^{2}$. The scan velocity was varied between $0.17-5 \mathrm{~cm} / \mathrm{s}$, and hence a fluence in the range of $1.5-150 \mathrm{~J} / \mathrm{cm}^{2}$ was applied to the glass surface. Micrographs of the channel waveguides were obtained using an analytical scanning electron microscope (SEM, JEOL 6400) to which an energy dispersive $\mathrm{X}$-ray microscope (EDAX), allowing compositional analysis, was attached. Surface compaction was evaluated using atomic force microscopy (AFM, Tencor Instruments Alpha-Step 200). The micrograph in Fig. 2 shows a representative channel 
directly written into Ga:La:S glass with UV-laser fluence of $10.8 \mathrm{~J} / \mathrm{cm}^{2}$. In this case, photostructural changes in the form of giant-photocompaction $(1.2 \mu \mathrm{m})$ and a region of refractive index change, with physical channel dimensions of $13 \mu \mathrm{m}$ by $6 \mu \mathrm{m}$, were observed. Measurements within the photomodified region revealed variations in elemental ratios, with an increase in lanthanum content and a decrease in gallium and sulphur. Compositional analysis (EDAX) of the waveguide core (exposed region) for channels exposed to $4.5,7.2$, and $10.8 \mathrm{~J} / \mathrm{cm}^{2}$ of laser energy revealed the lanthanum content to be $57.2 \mathrm{wt} \%$, $65.7 \mathrm{wt} \%$, and $67.6 \mathrm{wt} \%$, respectively. Measurements of the unexposed region showed lanthanum content to be $50.2 \mathrm{wt} \%$. This photochemical modification contributes to densification by creating a region of raised refractive index, which is the waveguide core. The physical size of a channel as well as the chemical change within the photoinduced region varied largely with changes in scan velocity and applied power density, as would be expected. This physical and chemical change in turn varied the attenuation as well as modal size and shape of the waveguide output. The maximum refractive index change in these channels, measured via the trigonometric method [28], was $\Delta n \approx+10^{-3}$.

It is well known that amorphous semiconductors (ChGs) can experience structural changes, with modification of physical and chemical states, when exposed to light. Chalcogenide glasses are widely regarded as a "soft semiconductor" because of their inherently quasi-stable atomic structure. The flexible and viscous structure is due to the chalcogen atoms having a twofold coordination. Electronic mobility, as seen in a semiconductor, produces asymmetric motion of atoms, and this can be used to explain some of the photoinduced effects in ChGs. However, it is certainly plausible that there are contributions from both electronic and thermal phenomena to these photoinduced effects [29].

Fractional volume expansion $(+\Delta V / V)$ upon light illumination is commonly observed in $\mathrm{As}_{2} \mathrm{~S}_{3}, \mathrm{As}_{2} \mathrm{Se}_{3}$, and $\mathrm{Ga}_{10} \mathrm{Ge}_{25} \mathrm{~S}_{65}$ glasses, but is not the only monitored volume change in ChGs [29]-[33]. Volume contraction $(-\Delta V / V)$ has also been reported in $\mathrm{GeAs}_{4} \mathrm{Se}_{5}, \mathrm{GeSe}_{2}$, and Ga:La:S glasses. Illumination of $\mathrm{SiO}_{2}$ glass, which has a disordered three-dimensional (3-D) random network structure, also leads to radiation compaction $(-\Delta V / V)$ [34]. In the case of $\mathrm{GeAs}_{4} \mathrm{Se}_{5}$, the structure is assumed to be fairly random and 3-D and exhibits radiation compaction [30]. The structural units for $\mathrm{GeSe}_{2}$ glass are nonlayered and 3-D. Here, volume contraction upon illumination is thought to arise due to a reduction in bond angle at the $\mathrm{Se}$ atom position in the Ge-Se-Ge bond as a result of the Ge-Ge atoms getting closer to each other [35]. The structural model for Ga:La:S glass has previously been studied by extended X-ray absorption fine structure (EXAFS, gallium K-edge, lanthanum LIII edge) spectroscopy. The proposed model for this glass type is the modified random network, which is a well-defined environment with a covalent network of $\mathrm{GaS}_{4}$ tetrahedra intercalated by the essentially ionic La-S channels [36]. The basic structure is assumed to be similar to $\mathrm{SiO}_{2}$ glass and also exhibits radiation compaction $(-\Delta V / V)$. In any case, diffraction pattern studies for both oxide and ChGs have shown similar results. Irradiation seems

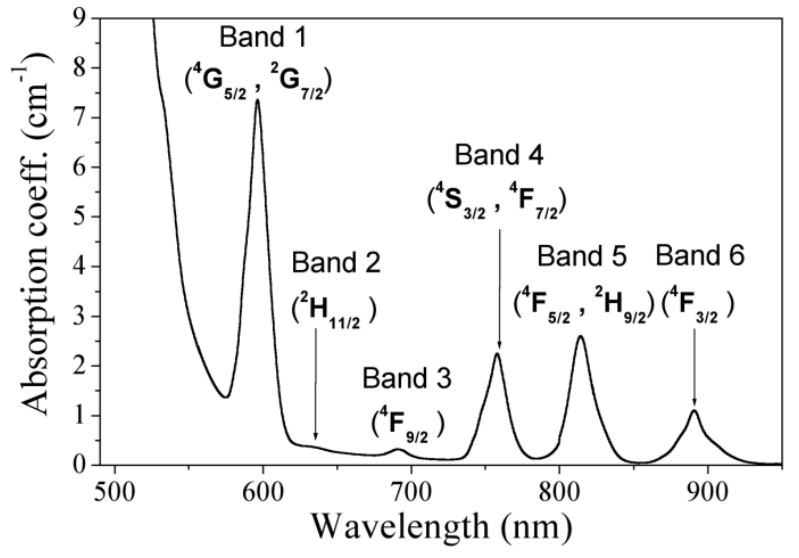

Fig. 3. Room-temperature absorption spectrum of $\mathrm{Nd}^{3+}{ }_{-} \mathrm{Ga}: \mathrm{La}: \mathrm{S}(0.5 \mathrm{wt} \%$ $\mathrm{Nd}_{2} \mathrm{~S}_{3}$ ) glass.

always to enhance the randomness of an amorphous structure, subsequently exciting electron-hole pairs which cooperatively produce structural transformations.

\section{SPECTROSCOPY AND LASER CHARACTERIZATION}

The ground-state absorption spectrum from 500 to $1000 \mathrm{~nm}$ was measured at room temperature for a Ga:La:S sample doped with $0.5 \mathrm{wt} \%$ of $\mathrm{Nd}_{2} \mathrm{~S}_{3}$, corresponding to a $\mathrm{Nd}^{3+}$ ionic concentration of $5.1 \times 10^{19}$ ion.cm ${ }^{-3}$, and is shown in Fig. 3. The spectrum, with 0.2-nm resolution, was recorded using a Varian Cary 500 Scan UV-VIS-NIR spectrophotometer. Ground state absorption bands from the ${ }^{4} \mathrm{I}_{9 / 2}$ level to ${ }^{4} \mathrm{~F}_{3 / 2},\left({ }^{4} \mathrm{~F}_{5 / 2},{ }^{2} \mathrm{H}_{9 / 2}\right)$, $\left({ }^{4} \mathrm{~S}_{3 / 2},{ }^{4} \mathrm{~F}_{7 / 2}\right),{ }^{4} \mathrm{~F}_{9 / 2},{ }^{2} \mathrm{H}_{11 / 2}$, and $\left({ }^{4} \mathrm{G}_{5 / 2},{ }^{2} \mathrm{G}_{7 / 2}\right)$ energy levels are identified. The electronic edge of the host glass lies close to $0.55 \mu \mathrm{m}$ and as a result obscures higher energy levels of the rare earth $\left({ }^{2} \mathrm{~K}_{13 / 2},{ }^{4} \mathrm{G}_{7 / 2},{ }^{4} \mathrm{G}_{9 / 2} \ldots\right)$. The absorption cross section as calculated from the spectrum gave a value of $5.1 \times 10^{-20} \mathrm{~cm}^{2}$ at $814 \mathrm{~nm}$.

A Judd-Ofelt analysis was performed with the absorption spectrum in order to determine the radiative parameters for the ${ }^{4} \mathrm{~F}_{3 / 2} \rightarrow{ }^{4} \mathrm{I}_{J}(J=9 / 2,11 / 2,13 / 2$ and $15 / 2)$ transitions. In the Judd-Ofelt model, the calculated line strength of electricdipole transitions between the initial state of angular momentum quantum number $J$ and the terminal state of angular momentum quantum number $J^{\prime}$ can be written in the form [37]

$$
S_{\text {ed(calc) }}\left(J, J^{\prime}\right)=e^{2} \sum_{t=2,4,6} \Omega_{t}\left|\left\langle\Psi J|| U^{(t)}|| \Psi^{\prime} J^{\prime}\right\rangle\right|^{2}
$$

where $\Omega_{(t)}$ are the Judd-Ofelt parameters and $\left|\left\langle\Psi J|| U^{(t)}|| \Psi^{\prime} J^{\prime}\right\rangle\right|^{2}$ are the reduced matrix elements. These elements are independent of the host material and have been calculated in [38]. The line strengths can be experimentally measured from absorption spectra integration using the equation

$S_{\text {ed(meas })}\left(J, J^{\prime}\right)=\frac{3 h c \varepsilon_{0}(2 J+1)}{2 \pi^{2} N \bar{\lambda}} \frac{\left(n^{2}+2\right)^{2}}{9 n} \int_{J \rightarrow J^{\prime}} \alpha(\lambda) d \lambda$ 
TABLE I

MEASURED $\left(S_{\text {ed(meas })}\right)$ AND CALCULATED $\left(S_{\text {ed(calc) }}\right)$ ABSORPTION LINE STRENGTHS, FITTED $\Omega(t)$ INTENSITY PARAMETERS,AND RMSDEVIATION $\delta_{\text {rms }}$ FOR Nd ${ }^{3+}$ IN GA:LA:S GLASS

\begin{tabular}{cccc}
\hline Band & Transition & $\mathrm{S}_{\text {ed (meas) }}$ & $\mathrm{S}_{\text {ed (calc) }}$ \\
& & $\left(10^{-20} \mathrm{~cm}^{2}\right)$ & $\left(10^{-20} \mathrm{~cm}^{2}\right)$ \\
\hline 1 & ${ }^{4} \mathrm{I}_{9 / 2} \rightarrow{ }^{4} \mathrm{G}_{5 / 2},{ }^{2} \mathrm{G}_{7 / 2}$ & 12.15 & 12.15 \\
4 & ${ }^{4} \mathrm{I}_{9 / 2} \rightarrow{ }^{4} \mathrm{~S}_{3 / 2},{ }^{4} \mathrm{~F}_{7 / 2}$ & 3.11 & 3.11 \\
5 & ${ }^{4} \mathrm{I}_{9 / 2} \rightarrow{ }^{4} \mathrm{~F}_{5 / 2},{ }^{2} \mathrm{H}_{9 / 2}$ & 3.79 & 3.80 \\
6 & ${ }^{4} \mathrm{I}_{9 / 2} \rightarrow{ }^{4} \mathrm{~F}_{3 / 2}$ & 1.66 & 1.65 \\
$\Omega_{2}=8.43 \times 10^{-20}$ & $\mathrm{~cm}^{2}$ & \\
$\Omega_{4}=6.17 \times 10^{-20}$ & $\mathrm{~cm}^{2}$ \\
$\Omega_{6}=4.27 \times 10^{-20}$ & $\mathrm{~cm}^{2}$ \\
& \\
$\delta_{\mathrm{rms}}=0.014 \times 10^{-20}$ & $\mathrm{~cm}^{2}$ \\
\hline
\end{tabular}

where $n$ is the refractive index of the sample, $N$ is the concentration of the dopant ion, $\alpha$ the absorption coefficient, $\bar{\lambda}$ is the mean wavelength, and the other symbols have their usual meanings. The Judd-Ofelt parameters $\Omega_{(t)}$ are fitted via (2) to the measured values from (3), using a computerized least square fit program. The quality of the adjustment can be measured by the rms deviation

$$
\delta_{\mathrm{rms}}=\sqrt{\frac{\sum_{i=1}^{q}\left(S_{\text {ed(meas })}-S_{\text {ed(calc) }}\right)^{2}}{q-3}}
$$

where $q$ is the number of absorption bands and 3 reflects the number of fitted parameters. To estimate the values of the Judd-Ofelt parameters in our host, we have calculated the line strengths for the four strongest absorption bands (bands 1, 4, 5 , and 6). In the case of bands 1,4 , and 5, the energy levels are too closely spaced to be treated separately. In these cases, the absorption spectrum was integrated over the whole band, the corresponding line strength was then calculated using (3), and this value was then fitted to the sum of the appropriate oscillator strengths from (2). Dispersion of the refractive index was also taken into account. Table I contains values of $S_{\text {ed(meas) }}$ and $S_{\text {ed(calc) }}$ for each absorption band, along with the fitted Judd-Ofelt parameters and the value of $\delta_{r m s}$. The determined Judd-Ofelt parameters then allow calculation of the transition rates for the transitions from the ${ }^{4} \mathrm{~F}_{3 / 2}$ to the ${ }^{4} \mathrm{I}_{9 / 2}$, ${ }^{4} \mathrm{I}_{11 / 2},{ }^{4} \mathrm{I}_{13 / 2}$, and ${ }^{4} \mathrm{I}_{15 / 2}$ manifolds. Using the appropriate matrix elements and (2), transition rates may be expressed as

$$
A\left(J, J^{\prime}\right)=\frac{16 \pi^{3}}{3 h \varepsilon_{0}\left(2 J_{a}+1\right) \bar{\lambda}^{3}} \frac{n\left(n^{2}+2\right)^{2}}{9} S_{\text {ed }}\left(J, J^{\prime}\right) .
$$

TABLE II

RAdiATIVE PARAMETERS FOR Nd ${ }^{3+}$ IN GA:LA:S GLASS FOR THE ${ }^{4} \mathrm{~F}_{3 / 2} \rightarrow{ }^{4} \mathrm{I}_{J}(J=9 / 2,11 / 2,13 / 2$, AND $15 / 2)$ TRANSITIONS

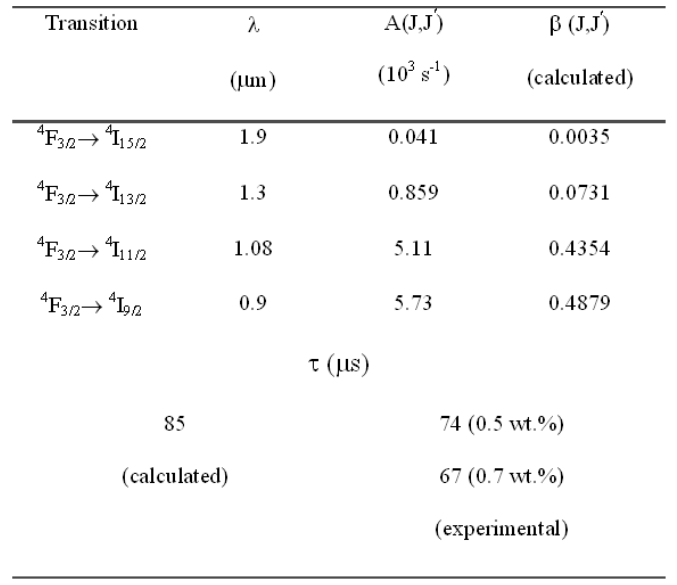

From the $A\left(J, J^{\prime}\right)$ probabilities, the radiative lifetime of the ${ }^{4} \mathrm{~F}_{3 / 2}$ manifold and the inter manifold luminescence branching ratios $\beta\left(J, J^{\prime}\right)$ were calculated by

$$
\begin{aligned}
\tau_{\text {rad }} & =\left(\sum_{J^{\prime}} A\left(J, J^{\prime}\right)\right)^{-1} \\
\beta\left(J, J^{\prime}\right) & =\tau_{\text {rad }} A\left(J, J^{\prime}\right) .
\end{aligned}
$$

The calculated transition probabilities and branching ratios for these transitions, as well as calculated radiative lifetime and experimental fluorescence lifetimes measured for $0.5 \mathrm{wt} \%$ and $0.7 \mathrm{wt} \% \mathrm{Nd}_{2} \mathrm{~S}_{3}$ in Ga:La:S glass, are reported in Table II. Experimental lifetimes were determined from single exponential fits to the decay of the fluorescence signal. Fluorescence decays were measured by exciting the samples using $5-\mu$ s pulses of modulated light from a Ti:sapphire laser operating at $814 \mathrm{~nm}$ and were monitored using a high-bandwidth InGaAs photodetector. An acoustooptic modulator was used to provide the modulation. Measured lifetimes are in good agreement with the calculated radiative lifetime. This agreement was expected as the host glass has low phononenergy and therefore a negligible multiphonon nonradiative decay probability. Measured values are slightly lower and decrease with increasing dopant concentration, due to interaction between doping ions, which is not taken into account in the Judd-Ofelt model.

A Ti:sapphire laser, tuned to $814 \mathrm{~nm}$, was also used to measure the room-temperature fluorescence spectrum of a Ga:La:S sample doped with $0.5 \mathrm{wt} \% \mathrm{Nd}_{2} \mathrm{~S}_{3}$. Intense emissions were expected around 900 and $1080 \mathrm{~nm}$ due to their higher branching ratios. The spectrum recorded by an optical spectrum analyzer is presented in Fig. 4. The ${ }^{4} \mathrm{~F}_{3 / 2} \rightarrow{ }^{4} \mathrm{I}_{11 / 2}$ emission cross section, the transition of particular interest for this paper, is also presented (inset). It was calculated from the fluorescence spectrum of the band and the values of the calculated branching ratio and radiative lifetime which are given in Table II, using the Füchtbauer-Ladenburg equation [39]

$$
\sigma_{\mathrm{em}, \mathrm{FL}}\left(J, J^{\prime}\right)=\frac{\beta\left(J, J^{\prime}\right) \lambda^{5} I\left(J, J^{\prime}\right)}{8 \pi n^{2} c \tau_{\mathrm{rad}} \int \lambda I\left(J, J^{\prime}\right) d \lambda} .
$$




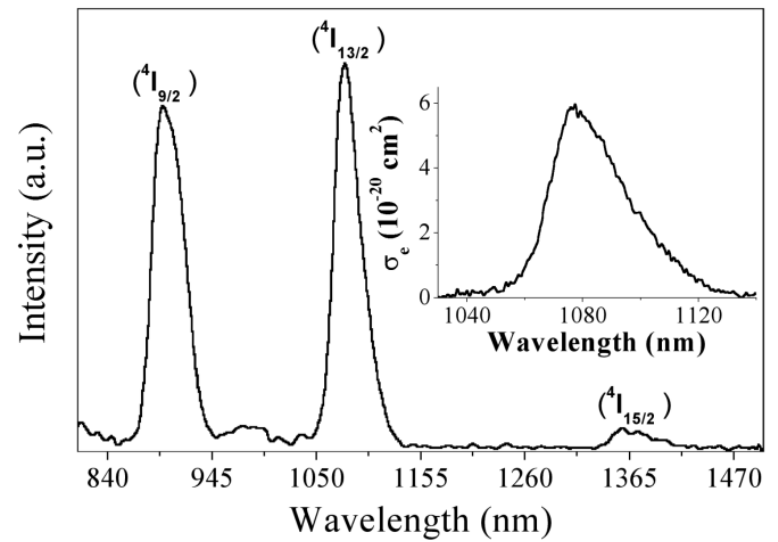

Fig. 4. Room-temperature emission spectrum in the near infrared for $\mathrm{Nd}^{3+}$-Ga:La:S $\left(0.5\right.$ wt $\left.\% \mathrm{Nd}_{2} \mathrm{~S}_{3}\right)$ waveguide. Inset shows the stimulated emission cross section at room temperature for the ${ }^{4} \mathrm{~F}_{3 / 2} \rightarrow^{4} \mathrm{I}_{11 / 2}$ transition.

The peak emission cross section at $1075 \mathrm{~nm}$ is $\sim$ $5.9 \times 10^{-20} \mathrm{~cm}^{2}$. This value is consistent with expectation for covalent host materials with high refractive index and is close to reported values for other chalcogenide glasses [40], [41].

The laser performance of our channel waveguides was tested using the 1075-nm ${ }^{4} \mathrm{~F}_{3 / 2} \rightarrow{ }^{4} \mathrm{I}_{11 / 2}$ transition, allowing an assessment of the propagation loss and potential use of these devices as lasers. The channel waveguide characterized was written with $I_{\mathrm{UV}}=10.2 \mathrm{~kW} / \mathrm{cm}^{2}$ and $V_{\mathrm{SCAN}}=4 \mathrm{~cm} / \mathrm{s}$ giving an applied fluence of $6.3 \mathrm{~J} / \mathrm{cm}^{2}$. The device length was $16 \mathrm{~mm}$ with doping concentration $0.7 \mathrm{wt} \%$ of $\mathrm{Nd}_{2} \mathrm{~S}_{3}$. The physical dimensions of the particular waveguide used for these lasing experiments were not fully measured (as removing the gold coating required for the SEM can damage the glass) but the compaction depth $(0.2 \mu \mathrm{m})$ and width $(8 \mu \mathrm{m})$ were much smaller than for the guide shown in Fig. 2. Laser light from a tunable Ti:sapphire was coupled into the waveguide using a single-launch X 6.3 microscope objective. Guided light from the waveguide was collected with a X10 microscope objective and directed through a mask to isolate light from the guided mode of the waveguide from that of the substrate. The single-pass absorption efficiency at $814 \mathrm{~nm}$ was measured by comparing the output power from the waveguide at two wavelengths, one in the absorption band and one off absorption, at constant pump power. A value of $\sim 99 \%$ was measured. This high absorption efficiency was expected due to the large absorption cross section. Optimization of launch efficiency was performed with the aid of a CCD camera, allowing observation of the channel mode, as well as through fluorescence intensity measurements. A launch efficiency of $\sim 30 \%$ was calculated from transmission measurements with the Ti:sapphire tuned off the $\mathrm{Nd}^{3+}$ absorption band. The rather low value for the launch efficiency was possibly due to the mismatch between the launched pump beam profile and the guided pump mode profile in the waveguide. In order to form the laser cavity, lightweight thin mirrors were butted to the end faces of the guide, using a thin film of fluorinated liquid for adherence. The input mirror $\left(R_{1}\right)$ was $98 \%$ reflective at the lasing wavelength $(1075 \mathrm{~nm})$ and had $87 \%$ transmission at the pump wavelength

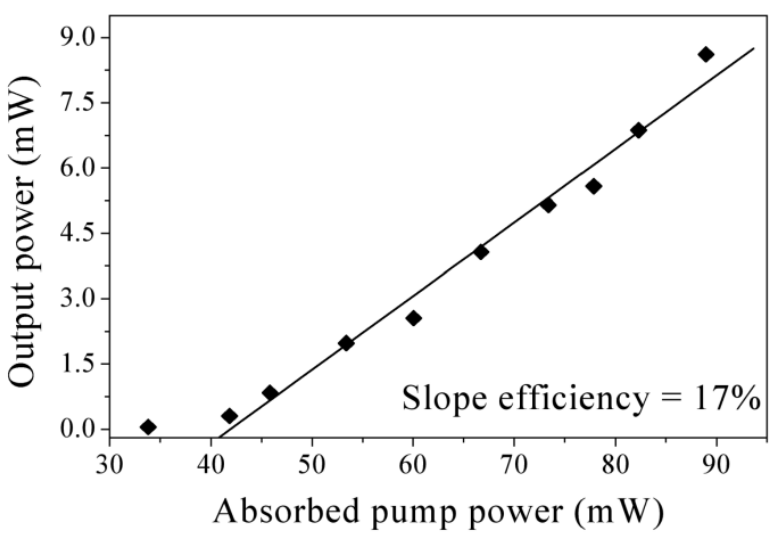

Fig. 5. Output power against absorbed pump power for a $\mathrm{Nd}^{3+}{ }_{-} \mathrm{Ga}: \mathrm{La}: \mathrm{S}(0.7$ wt $\% \mathrm{Nd}_{2} \mathrm{~S}_{3}$ ) channel waveguide laser.

(814 nm). Three sets of output mirrors with different reflectivities $\left(R_{2}\right)$ were utilized with $2 \%, 8 \%$, and $12.5 \%$ transmission at the signal wavelength. Lasing threshold was noted for each case. With the $2 \%$ output coupler, the threshold was as low as $15.1 \mathrm{~mW}$ of absorbed pump power and increased to $18.7 \mathrm{~mW}$ with the $8 \%$ output coupler. With the $12.5 \%$ output coupler, the threshold rose to $34 \mathrm{~mW}$ with laser output results shown in Fig. 5. The maximum output power available with this configuration was $8.6 \mathrm{~mW}$ for $89 \mathrm{~mW}$ of absorbed pump power with a slope efficiency of $17 \%$. Measurement of the laser output with an optical spectrum analyzer revealed a lasing wavelength of $1075 \mathrm{~nm}$. This is at the same wavelength at which the fluorescence emission spectrum has maximum intensity and corresponds to the wavelength of maximum internal gain. Observation and measurements of the pump and lasing mode were performed with a CCD camera, and it was observed that both the pump and laser output were in the fundamental spatial mode. Modal dimensions $\left(1 / e^{2}\right.$ radius of intensity) were $W_{p x}=7.5 \mu \mathrm{m}$ by $W_{p y}=6.6 \mu \mathrm{m}$ for the pump mode and $W_{l x}=10.1 \mu \mathrm{m}$ by $W_{l y}=7.8 \mu \mathrm{m}$ for the laser mode. The size of the waveguide mode would appear to be much larger than the physical dimension of the waveguide structure, which is again indicative of single-mode behavior.

Evaluation of the propagation loss, which is a crucial parameter for such devices, was estimated first by the Findlay-Clay method [42]. For a four-level waveguide laser system with negligible depopulation of the ground state, the absorbed pump power at threshold ( $\left.P_{\text {th abs }}\right)$ can be expressed as

$$
P_{\text {th abs }}=K\left(2 \alpha_{L} \ell-\ln \left(R_{1} R_{2}\right)\right)
$$

where $K$ is a constant dependent upon the material parameters and the pump and signal spatial properties, $\alpha_{L}$ is the waveguide propagation attenuation coefficient, $\ell$ is the device length, and $R_{1}$ and $R_{2}$ are the reflectivities of the input and output mirrors at the laser wavelength. The value for the attenuation coefficient $\alpha_{L}$ can be determined from this expression without knowing the value of $K$, simply by plotting $P_{\text {th abs }} / \ell$ versus $-\ln \left(R_{1} R_{2}\right) / 2 \ell$ as shown in Fig. 6. The intercept on the $x$ axis is indicative of the propagation attenuation coefficient in the laser cavity and gives a value of $\alpha_{L} \sim 3 \mathrm{~m}^{-1}\left(\sim 0.1 \mathrm{~dB} \mathrm{~cm}^{-1}\right)$. 


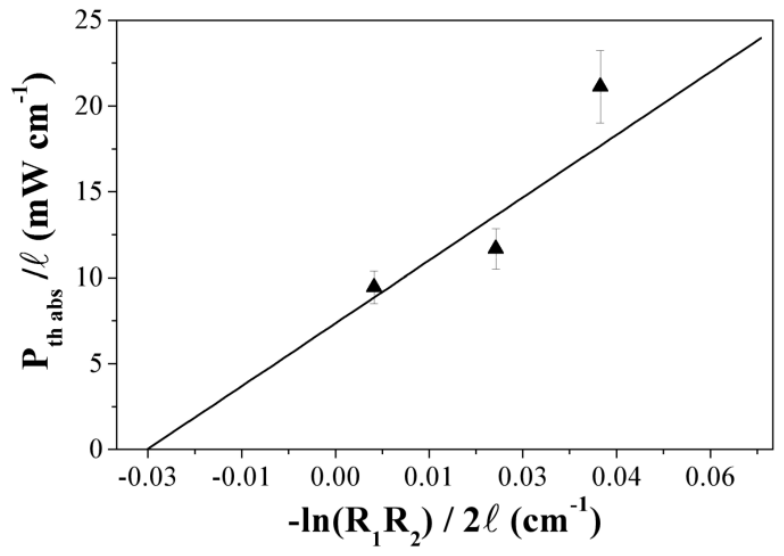

Fig. 6. Plot of $P_{\text {th abs }} / \ell$ against $-\ln \left(R_{1} R_{2}\right) / 2 \ell$ where the intercept with the $x$ axis gives the waveguide propagation attenuation coefficient $\alpha_{L}=3 \mathrm{~m}^{-1}$.

Due to the lack of output couplers with higher transmission at the signal wavelength, this value has a fairly high uncertainty and so the attenuation figure was confirmed through two further separate calculations. The first method involves an estimation of the attenuation through correlation of the experimental laser threshold with the theoretical expression given in (9). For a longitudinally pumped system, the constant $K$ can be calculated as [43]

$$
K=\frac{\pi h v_{p}}{4 \sigma_{e} \tau} \sqrt{W_{l x}^{2}+W_{p x}^{2}} \sqrt{W_{l y}^{2}+W_{p y}^{2}}
$$

where $h$ is Planck's constant, $v_{p}$ is the pump frequency, $\sigma_{e}$ is the emission cross section, $\tau$ is the fluorescence lifetime, and $W_{l x}, W_{l y}, W_{p x}$, and $W_{p y}$ refer to the $1 / e^{2}$ intensity radii for the laser and pump modes in the horizontal and vertical planes, respectively. For the experimental values of $P_{\text {th }}$ abs found using the $R_{2}=98 \%$ and $92 \%$, we find values for the propagation loss of $<0.4 \mathrm{~dB} \mathrm{~cm}^{-1}$, whereas a higher value of $0.7 \mathrm{~dB} \mathrm{~cm}^{-1}$ is calculated for the $R_{2}=87.5 \%$ value.

Another approach for determining waveguide attenuation involves analysis of the slope efficiency $(\eta)$ using the relation [44]

$$
\begin{aligned}
\eta=\eta_{q} \cdot \frac{v_{l}}{v_{p}} \cdot \frac{-\ln \left(R_{2}\right)}{-\ln \left(R_{1} R_{2}\right)+2 \alpha_{L}} \\
\\
\cdot \frac{W_{l x} W_{l y}\left(2 W_{p x}^{2}+W_{l x}^{2}\right)^{1 / 2}\left(2 W_{p y}^{2}+W_{l y}^{2}\right)^{1 / 2}}{\left(W_{p x}^{2}+W_{l x}^{2}\right)\left(W_{p y}^{2}+W_{l y}^{2}\right)}
\end{aligned}
$$

where $\eta_{q}$ is quantum efficiency of the device (assumed to be $100 \%$ ), and $v_{l}$ is the laser frequency. Assuming all propagation losses are due to the waveguide, the experimental upper limit for attenuation, as calculated from (11) for $\eta=17 \%$ and $R_{2}=12.5 \%$, is $<0.5 \mathrm{~dB} \mathrm{~cm}^{-1}$. Taking into account the variation in values given by the three methods of calculating the propagation loss, we can give a final figure of $<0.5 \mathrm{~dB} \mathrm{~cm}^{-1}$. This attenuation figure is comparable to that found by white light transmission measurements in similar passive waveguides [24]. It is also interesting to note that the emission cross section found from our spectroscopic analysis is consistent with the observed laser performance.

The lasing results described here represent an initial demonstration and are far from what might be expected in an optimized lasing device. Improvements should arise through optimization of the writing process to produce the lowest loss single-mode guides as well as taking care over use of optimized parameters for laser performance, such as the doping level and the length of waveguide. However, these results also clearly show the potential for active IO devices based on these low loss optically written waveguides.

\section{Summary}

We have demonstrated the fabrication of low-loss optically written channel waveguides in a chalcogenide glass by scanning a focused UV-laser beam $(\lambda=244 \mathrm{~nm})$ across the sample surface. Volume compaction was observed upon illumination with compaction depths ranging from 0.2 to $1.3 \mu \mathrm{m}$, depending on the writing parameters, while ablation and microcracking were the dominant effects for very high applied fluencies. Photochemical modification in the guided regions was also observed and verified through EDAX measurements, and the maximum measured refractive index change in these channels was $\Delta n \approx$ $+10^{-3}$. A channel waveguide written with an applied fluence of $6.3 \mathrm{~J} / \mathrm{cm}^{2}$ was characterized to be spatially single-mode with a maximum laser output $(\lambda=1075 \mathrm{~nm})$ of $8.6 \mathrm{~mW}$ for an absorbed laser pump power of $89 \mathrm{~mW}$. A slope efficiency of $17 \%$ was achieved with attenuation in this device measured to be $<0.5 \mathrm{~dB} \mathrm{~cm}^{-1}$. These results were in agreement with a peak emission cross section of $5.9 \times 10^{-20} \mathrm{~cm}^{2}$ calculated from a Judd-Ofelt analysis.

With the combination of high refractive index, low phononenergy, and the relative ease of fabricating high-quality low-loss waveguides, Ga:La:S glass is indeed an exciting candidate for efficient IO devices. High purity powders, with low transition metal $(<1 \mathrm{ppm})$ and water $\left(\mathrm{OH}^{-}\right)$content, will lead to enhanced glass quality, and improving the stability and reliability of laser write parameters will increase the reproducibility of high-quality waveguides allowing a systematic optimization of the waveguide properties. Thus, the potential for developing passive and active optical waveguides in the Ga:La:S glass system for IO devices and near-mid-IR sources seems promising, and the investigation of erbium-doped devices is currently underway.

\section{REFERENCES}

[1] S. E. Miller, "Integrated optics: An introduction," Bell Syst. Tech. J., vol. 48, pp. 2059-2069, 1969.

[2] K. Worhoff, A. Driessen, P. V. Lambeck, L. T. H. Hilderink, P. W. C. Linders, and T. J. A. Popma, "Plasma enhanced chemical vapor deposition silicon oxynitride optimized for application in integrated optics," Sens. Actuat. A (Phys.), vol. A74, pp. 9-12, 1999.

[3] K. Shuto, K. Hattori, T. Kitagawa, Y. Ohmori, and M. Horiguchi, "Erbium-doped phosphosilicate glass waveguide amplifier fabricated by PECVD," Electron. Lett., vol. 29, pp. 139-141, 1993.

[4] M. Svalgaard, C. V. Poulsen, A. Bjarklev, and O. Poulsen, "Direct UV writing of buried singlemode channel waveguides in Ge-doped silica films," Electron. Lett., vol. 30, pp. 1401-1403, 1994.

[5] T. Kitagawa, K. Hattori, Y. Hibino, and Y. Ohmori, "Neodymium-doped silica-based planar waveguide lasers," J. Lightwave Technol, vol. 12, pp. 436-442, 1994.

[6] R. M. Almeida, "Sol-gel planar waveguides for integrated optics," $J$. Non-Cryst. Sol., vol. 259, pp. 176-181, 1999.

[7] K. M. Mwarania, J. Wang, J. Lane, and J. S. Wilkinson, "Neodymiumdoped ion-exchanged waveguide lasers in BK-7 glass," J. Lightwave Technol, vol. 11, pp. 1550-1558, 1993. 
[8] J. Lucas, "Fluoride glasses," Current Opinion in Solid State \& Materials Science, vol. 2, pp. 405-411, 1997.

[9] L. B. Shaw, B. Cole, P. A. Thielen, J. S. Sanghera, and I. D. Aggarwal, "Mid-wave IR and long-wave IR laser potential of rare-earth doped chalcogenide glass fiber," IEEE J. Quantum Electron., vol. 37, pp. 1127-1137, 2001.

[10] E. Josse, G. Fonteneau, and J. Lucas, "Low-phonon waveguides made by $\mathrm{F}^{-} / \mathrm{Cl}^{-}$exchange on fluoride glasses," Mat. Res. Bull., vol. 32, pp. 1139-1146, 1997.

[11] E. Lebrasseur, B. Jacquier, M. C. M. de Lucas, E. Josse, J. L. Adam, G. Fonteneau, J. Lucas, Y. Gao, B. Boulard, C. Jacoboni, J. E. Broquinand, and R. Rimet, "Optical amplification and laser spectroscopy of neodymium-doped fluoride glass channel waveguides," J. Alloys Compounds, vol. 275-277, pp. 716-720, 1998.

[12] Y. Gao, B. Boulard, M. Lemiti, R. Rimet, P. Loeffler, and H. Poignant, "Design and fabrication of lead-based fluoride glass channel waveguides," J. Non-Cryst. Sol., vol. 256-257, pp. 183-188, 1999.

[13] E. Lebrasseur, Y. Gao, B. Boulard, and B. Jacquier, "Amplification in $\mathrm{Er}^{3+}$ doped PZG fluoride glass channel waveguides," in ECOC, vol. 1, Nice, France, 1999, pp. 54-55

[14] J. Ballato, M. Dejneka, R. E. Riman, E. Snitzer, and Z. Weimin, "Sol-gel synthesis of rare-earth-doped fluoride glass thin films," J. Mat. Res., vol. 11, pp. 841-849, 1996.

[15] D. W. J. Harwood, A. Fu, E. R. Taylor, R. C. Moore, Y. D. West, and D. N. Payne, "A $1317 \mathrm{~nm}$ neodymium doped fluoride glass waveguide laser," in Proc. ECOC, vol. 2, Berlin, Germany, 2000, pp. 191-192.

[16] K. Miura, Q. Jianrong, T. Mitsuyu, and K. Hirao, "Preparation and optical properties of fluoride glass waveguides induced by laser pulses," $J$. Non-Cryst. Sol., vol. 256-257, pp. 212-219, 1999.

[17] T. Schweizer, D. W. Hewak, B. N. Samson, and D. N. Payne, "Spectroscopy of potential mid-infrared laser transitions in gallium lanthanum sulphide glass," J. Lumines., vol. 72-74, pp. 419-421, 1997.

[18] A. E. Owen, A. P. Firth, and P. J. S. Ewen, "Photo-induced structural and physico-chemical changes in amorphous chalcogenide semiconductors," Philosoph. Mag. B, vol. 52, pp. 347-362, 1985.

[19] C. Gmachl, H. Y. Hwang, R. Paiella, D. L. Sivco, J. N. Baillargeon, F Capasso, and A. Y. Cho, "Quantum cascade lasers with low-loss chalcogenide lateral waveguides," IEEE Photon. Technol. Lett., vol. 13, pp. 182-184, 2001

[20] A. Saliminia, A. Villeneuve, T. V. Galstyan, S. LaRochelle, and K Richardson, "First and second order Bragg gratings in single-mode planar waveguides of chalcogenide glasses," J. Lightwave Technol., vol. 17, pp. 837-842, 1999

[21] X. Jian and R. M. Almeida, "Sol-gel derived germanium sulfide planar waveguides," in Mat. Sci. Semicond. Process., 2000, vol. 3, pp. 339-344.

[22] J. F. Viens, C. Meneghini, A. Villeneuve, T. V. Galstian, E. J. Knystautas, M. A. Duguay, K. A. Richardson, and T. Cardinal, "Fabrication and characterization of integrated optical waveguides in sulfide chalcogenide glasses," J. Lightwave Technol., vol. 17, pp. 1184-1191, 1999.

[23] O. M. Efimov, L. B. Glebov, K. A. Richardson, E. Van Stryland, T. Cardinal, S. H. Park, M. Couzi, and J. L. Bruneel, "Waveguide writing in chalcogenide glasses by a train of femtosecond laser pulses," Opt. Mat., vol. 17, pp. 379-386, 2001.

[24] A. K. Mairaj, A. Fu, H. N. Rutt, and D. W. Hewak, "Optical channel waveguide in chalcogenide (Ga:La:S) glass," Electron. Lett., vol. 37, pp. $1160-1161,2001$

[25] A. M. L. Lozac'h, M. Guittard, and J. Flahaut, "Glasses formed by rare earth sulphides $\mathrm{L}_{2} \mathrm{~S}_{3}$ with gallium sulphide $\mathrm{Ga}_{2} \mathrm{~S}_{3}$," Mat. Res. Bull., vol. 11, pp. 1489-1496, 1976

[26] Y. D. West, T. Schweizer, D. J. Brady, and D. W. Hewak, "Gallium lanthanum sulphide fibers for infrared transmission," Fiber Integr. Opt., vol. 19, pp. 229-250, 2000

[27] A. K. Mairaj, C. Riziotis, A. M. Chardon, P. G. R. Smith, D. P. Shepherd, and D. W. Hewak, "Development of channel waveguide lasers in $\mathrm{Nd}^{3+}$-doped chalcogenide (Ga:La:S) glass through photoinduced material modification," Appl. Phys. Lett., to be published.

[28] J. M. Senior, Optical Fiber Communications: Principles and Practice, 2nd ed. Englewood Cliffs, NJ: Prentice-Hall, 1992, pp. 808-809.

[29] K. Tanaka, "Photoinduced processes in chalcogenide glasses," Current Opinion in Solid State \& Materials Science, vol. 1, pp. 567-571, 1996.

[30] H. Hamanaka, K. Tanaka, A. Matsuda, and S. Iizima, "Reversible photoinduced volume changes in evaporated $\mathrm{As}_{2} S_{3}$ and $\mathrm{As}_{4} \mathrm{Se}_{5} \mathrm{Ge}_{1}$ films," Solid State Commun., vol. 19, pp. 499-501, 1976.

[31] H. Hisakuni and K. Tanaka, "Optical fabrication of microlenses in chalcogenide glasses,” Opt. Lett., vol. 20, pp. 958-960, 1995.
[32] M. D. Mikhailov, E. A. Karpova, Z. Cimpl, and F. Kosek, "Photo and thermally induced change in the volume of thin chalcogenide films," Phys. Stat. Sol. A, vol. 117, pp. 467-475, 1990.

[33] S. H. Messaddeq, M. S. Li, D. Lezal, S. J. L. Ribeiro, and Y. Messaddeq, "Above bandgap induced photoexpansion and photobleaching in Ga-Ge-S based glasses," J. Non-Cryst. Sol., vol. 284, pp. 282-287, 2001.

[34] A. R. Silin, "Light-induced ionic processes in optical oxide glasses," $J$. Non-Cryst. Sol., vol. 129, pp. 40-45, 1991.

[35] A. Ganjoo, Y. Ikeda, and K. Shimakawa, "In situ measurements of photoinduced volume changes in amorphous chalcogenide films," J. NonCryst. Sol., vol. 266-269, pp. 919-923, 2000.

[36] S. Benazeth, M. H. Tuilier, A. M. Loireau-Lozac'H, H. Dexpert, P. Lagarde, and J. Flahaut, "An EXAFS structural approach of the lanthanumgallium-sulfur glasses," J. Non-Cryst. Sol., vol. 110, pp. 89-100, 1989.

[37] A. A. Kaminskii, Laser Crystals, D. L. MacAdam, Ed. Berlin, Germany: Springer-Verlag, 1981, vol. 14, Springer Series in Optical Scienses, pp. $148-165$

[38] T. Carnal, H. Crosswhite, and H. M. Crosswhite, "Energy Level Structure and Transition Probabilities of the Trivalent Lanthanides in $\mathrm{LaF}_{3}$," Argonne National Laboratory, Chemistry Division, IL, Rep. ANL-78-XX-95, 1978

[39] B. F. Aull and H. P. Jenssen, "Vibronic interactions in Nd:YAG resulting in nonreciprocity of absorption and emission cross sections," IEEE $J$. Quantum Electron., vol. QE-18, pp. 925-930, 1982.

[40] B. Viana, M. Palazzi, and O. LeFol, "Optical characterization of $\mathrm{Nd}^{3+}$ doped sulphide glasses," J. Non-Cryst. Sol, vol. 215, pp. 96-102, 1997.

[41] A. Bornstein and R. Reisfeld, "Laser emission cross-section and threshold power for laser operation at $1077 \mathrm{~nm}$ and $1370 \mathrm{~nm}$; Chalcogenide mini-lasers doped by $\mathrm{Nd}^{3+}$, " J. Non-Cryst. Sol, vol. 50, pp. 23-27, 1982.

[42] D. Findlay and R. A. Clay, "The measurement of internal losses in 4-level lasers," Phys. Lett., vol. 20, pp. 277-278, 1966.

[43] W. P. Risk, "Modeling of longitudinally pumped solid-state lasers exhibiting reabsorption losses," J. Opt. Soc. Amer. B, vol. 5, pp. $1412-1423,1988$

[44] W. A. Clarkson and D. C. Hanna, "Effects of transverse-mode profile on slope efficiency and relaxation oscillations in a longitudinally-pumped laser," J. Mod. Opt., vol. 36, pp. 483-498, 1989.

Arshad K. Mairaj was born in Singapore in 1974. He received two degrees in electronics from Ngee Ann Polytechnic, Singapore, and the B.Eng degree in electronics engineering from the University of Southampton, Southampton, U.K., in 2000. He is currently working toward the Ph.D. degree at the Optoelectronics Research Centre, Southampton, U.K.

His research interests include development of chalcogenide fiber as well as fabrication methods for planar and channel waveguides in novel hosts.

Mr. Mairaj is a member of the Optical Society of America.

Alain M. Chardon received the DEA degree (Diplôma d'Etudes Approfondies) in optoelectronics in 1993 and the Ph.D. degree in laser physics from the University of Rennes, Rennes, France, in 1996. His thesis topic involved research in diode-pumped microchip lasers.

Before beginning his doctoral studies, he worked for three years as a Research Assistant for the CNRS. In 1996, he was appointed Assistant Lecture at the Ecole Nationale Supérieure des Sciences Appliquées et de Technologie, Lannion, France. He joined the Department of Electrical Engineering, University of Pittsburgh, Pittsburgh, PA, as a Research Associate in 1997 where he worked on the development of diode-pumped, eye-safe, laser range finders. $\mathrm{He}$ then worked as Research Scientist at F.E.E. GmbH, Idar-Oberstein, Germany, in 1998, developing CW and pulsed microchip lasers. He joined the Optoelectronics Research Centre, Southampton, U.K., as a Research Fellow in 2000 where he is currently investigating rare-earth-doped fluoride waveguide devices for mid-infrared applications. 
David P. Shepherd received the B.Sc. degree in physics and the Ph.D. degree in laser physics from the University of Southampton, U.K., in 1985 and 1989, respectively. His thesis topic was the development of short-pulse sources at $1.5 \mu \mathrm{m}$ and involved research in Raman Scattering and Yb:Er:Glass bulk and fiber lasers.

He then worked as a Research Fellow in the Physics Department, and, from 1991, in the Optoelectronics Research Centre at the University of Southampton, investigating planar waveguide lasers based on rare-earth-ion and transition-metal-ion doped crystals and glasses. This included work on waveguides fabricated by ion-implantation, ion-diffusion, ion-exchange, liquid-phase-epitaxy, molecular-beam epitaxy, pulsed laser deposition, spin coating, and direct bonding. He is currently a Principal Research Fellow, leading a group investigating waveguide devices primarily for high-power diode-pumped laser sources. His research interests also include self-adaptive gain-grating lasers and synchronously-pumped optical parametric oscillators. He has published over 50 papers in scientific journals, mostly concerned with planar waveguide lasers.
Daniel W. Hewak received the Ph.D. degree from the University of Waterloo, ON, Canada, in 1989.

He then spent three years with the National Optics Institute working on polymer waveguides. He joined the Optoelectronics Research Centre, University of Southampton, Southampton, U.K., in 1991 where his research interests are novel glasses and waveguides. He is the Editor of the book Properties, Processing and Applications of Glass and Rare-Earth Doped Glasses for Optical Fibers and Section Editor of the Optical Materials section of Current Opinion in Solid State Materials. 